\title{
Activity level as a function of status and social isolation in the bluegill sunfish (Lepomis macrochirus Rafinesque)
}

\author{
ALCINE POTTS LUKENBACH and DAVID CHISZAR \\ University of Colorado, Muenzinger Building, Boulder, Colorado 80309
}

\begin{abstract}
Two experiments with bluegill sunfish (Lepomis macrochirus Rafinesque) showed that (1) dominant fish were more active in the home tank than subordinates and isolated individuals, and (2) dominants and subordinates did not differ in activity during the initial 20 min of inhabiting a new tank; but both of these animals exhibited higher activity levels than isolates placed into a new tank. Restricted activity of subordinate fish in the home tank may be based on the fact that movement elicits attacks from the dominant fish. Behavior of isolates in a new environment probably derives from increased fearfulness produced by social isolation.
\end{abstract}

Fish living in isolation are known to differ in a variety of ways from conspecifics living in groups. Usually the group situation is "facilitory" compared to social isolation (growth rate: Shaw, 1932; survival under adverse chemical conditions: Allee \& Bowen, 1932; maze learning: Greenberg, 1947; Hale, 1956; Welty, 1934; Wijffels, Thines, Dijkgraaf, \& Verheijen, 1967; metabolic rate: Allee, 1934; Schlaifer, 1938). However, this comparison is somewhat misleading because it implies that all individuals within a group enjoy the same advantages when they are compared with isolated subjects. This is almost certainly untrue because low-ranking members of hierarchical systems are sometimes found to have difficulty in securing food and maintaining body weight (Poulsen \& Chiszar, 1976), and, in some cases, they may be damaged or killed by dominant individuals (Chiszar, Drake, \& Windell, 1975; Huck \& Gunning, 1967; Henderson \& Chiszar, in press). Hence, great variation exists between individuals of hierarchies, and the lowest ranking animals, at least, may be in poorer condition than isolated ones. The purpose of the present study was to compare activity levels of dominant, subordinate, and isolated individuals to determine the extent to which this measure is correlated with status, as well as the extent to which isolates differ from dominants and subordinates.

The City of Boulder and the State of Colorado granted permission for the capture of fish employed in this research. Raymond C. Miles sponsors this paper and takes full editorial responsibility for its content. The authors thank the M. M. Schmidt Foundation for its financial support. Reprint requests should be sent to D. Chiszar.

\section{EXPERIMENT I: HOME TANK ACTIVITY IN DOMINANT, SUBORDINATE, AND ISOLATED FISH}

\section{Method}

All fish employed in this and the following experiment were bluegill sunfish (Lepomis macrochirus Rafinesque), captured by seining local ponds northeast of Boulder, Colorado. Although fish ranging in size from 5 to $12 \mathrm{~cm}$ (fork length) were captured, only individuals of approximately $9 \pm .5 \mathrm{~cm}$ were employed in these experiments. All fish were housed in small groups $(\mathrm{n}=5-8)$ in 120 -liter aquariums at $21-22^{\circ} \mathrm{C}$ for about 3 months prior to service in this study. The aquariums were equipped with bottom filters, gravel, and one or two large rocks. The laboratory light cycle ran from 0700 to 1900 , and subjects were fed (herring-meal pellets) daily at about 1200 .

Three days before an observation was to be taken, subjects were removed from the holding tanks, and each was placed either in a group of five to seven mutually naive fish or alone in a 95-liter aquarium (containing undergravel filters and rocks). Maintenance conditions were the same as above except that opaque dividers were placed between tanks to block visual stimulation from neighboring aquariums.

At the beginning of an observation session, the experimenter sat approximately $1 \mathrm{~m}$ directly in front of an aquarium and remained still for about $5 \mathrm{~min}$. An isolated fish was then observed for the next $20 \mathrm{~min}$. The total number of seconds spent in activity (i.e., anytime the fish was not stationary) was recorded during four successive 5-min blocks with the aid of a hand-held stopwatch. In the case of group tanks, the initial $5 \mathrm{~min}$ was spent deciding which fish were dominant (i.e., initiated chases but received none, and exclusively commanded a position that usually incorporated the rocks) and which were subordinate (i.e., initiated few or no chases but received some, and did not command a position from which other fish were excluded). Next, a dominant and subordinate fish would each be observed for $20 \mathrm{~min}$ as described above. A coin toss decided which kind of fish would be observed first. A total of five fish of each type were observed (i.e., isolates, dominants, and subordinates). ${ }^{1}$ 
Table 1

Mean Number of Seconds Spent in Activity by Dominant, Subordinate, and Isolated Bluegills During Four Successive 5-Min Observation Periods

\begin{tabular}{|c|c|c|c|c|}
\hline & \multicolumn{4}{|c|}{ Successive 5-Min Periods } \\
\hline & 1 & 2 & 3 & 4 \\
\hline Dominant & 122 & 123 & 120 & 100 \\
\hline Subordinate & 43 & 62 & 41 & 45 \\
\hline Isolate & 41 & 43 & 57 & 57 \\
\hline
\end{tabular}

\section{Results and Discussion}

Table 1 presents the mean number of seconds of activity for the three groups over 5-min time blocks. It is clear that dominant fish were more active than subordinate or isolated ones $(F=10.02$, df $=$ $2 / 12, p<.01)$. A separate ANOVA showed that the latter two groups did not differ $(F<1.0)$.

During an extended series of observations on four group tanks (35 5-min observations on each), the respective dominant individuals were found to be engaged in some form of aggressive act during $80 \%$ of the times that they were scored as "active." The remaining $20 \%$ of the activity periods involved gravel spitting, investigating rocks or air bubbles, or position changes which did not require displacement of another fish. Hence, it appears that the greater activity level of the dominant animal is occasioned mainly by his responsiveness to stimuli arising from the subordinates. The latter, on the other hand, tend to restrict their movement, probably because any movement makes them more conspicuous to the dominant fish. If movements by subordinate fish represent investigatory behavior as well as social behavior, the subordinates might be conceptualized as victims of a "learned disinterest" contingency imposed by dominant individuals. That is, since the dominants punish the subordinates for investigatory movement, the latter eventually discontinue such behavior, perhaps by ceasing to be interested in objects and events in the environment.

The isolated fish, having no social stimulation of any sort and very little ambient stimulation in their aquariums, simply remained inactive. Although the isolates and subordinates may curtail their respective activities for different reasons, it is interesting that they are statistically equal by the present measure. An important question at this point is: To what extent will the pattern of activity differences between dominant, subordinate, and isolated individuals persist when the animals are placed (as individuals) into a new situation? In Experiment II, bluegills of these three sorts were each transferred to an empty tank and proactive activity effects of previous housing-status conditions were measured.

\section{EXPERIMENT II: ACTIVITY IN A NEW AQUARIUM AS A FUNCTION OF PREVIOUS HOUSING-STATUS CONDITIONS}

\section{Method}

Six groups, containing four to six equal-sized bluegills, were maintained for approximately 2 weeks along with six individuals living alone in identical aquariums (120-liter, with the same , accessories described in Experiment I). Three of the isolates were previously dominant, and three were previously subordinate.

The transfer tank was similar in all respects to the home tanks. Individual fish were transferred quickly from the home tank to the new tank with the aid of a dip net. Activity was measured in the same manner described in Experiment I except that fish were observed through seven successive 5-min time blocks. Six dominants, six subordinates, and six isolates were observed in the transfer tank.

\section{Results and Discussion}

Mean number of seconds of activity is shown over successive time blocks for all three groups of fish in Table 2. A 3 by 7 (repeated measure) ANOVA revealed an insignificant group main effect $(\mathrm{F}=$ 2.18 , df $=2 / 15, \mathrm{p}>.05$ ) and a significant Group by Time Blocks interaction $(F=5.96, \mathrm{df}=12 / 90$, $\mathrm{p}<.01)$. The dominant and subordinate groups were analyzed separately, and no significant group main effect or interactions were revealed (all ps $>.05$ ). An additional ANOVA compared the three groups during only the first $10 \mathrm{~min}$, and a significant group main effect emerged $(F=26.56, d f=2 / 15$, $\mathrm{p}<.01)$. Hence, the overall Groups by Time Blocks interaction seen in the first ANOVA resulted from an initially lower activity level of the isolates.

Although activity level of subordinate fish was suppressed in the group situation (home tank), these individuals explored a new environment with as much vigor as dominant fish, indicating that any "learned disinterest" acquired by subordinates in their home tank did not generalize to the new one. However, the socially deprived animals were, at least

Table 2

Mean Number of Seconds Spent in Activity by Dominant, Subordinate, and Isolated Bluegills During Seven Successive 5-Min Periods in a New Aquarium

\begin{tabular}{lccccccc}
\hline & \multicolumn{7}{c}{ Successive 5-Min Periods } \\
\cline { 2 - 7 } & 1 & 2 & 3 & 4 & 5 & 6 \\
\hline Dominant & 158 & 159 & 175 & 146 & 140 & 140 & 138 \\
Subordinate & 210 & 186 & 180 & 191 & 175 & 190 & 150 \\
Isolate & 58 & 100 & 148 & 180 & 165 & 168 & 188 \\
\hline
\end{tabular}


initially, less vigorous in the transfer tank. (Isolates which were previously dominant did not differ from those which were previously subordinate, $F<1$.) We presume that this effect resulted from the high level of fearfulness or startle reactivity produced by isolation (Davis, 1976). However, within 10 to $15 \mathrm{~min}$ in the new environment, this gave way to the effects of stimulus novelty, and the isolates began to explore the new tank in a manner similar to the other groups.

\section{NOTE}

1. To check the reliability of the dominant-subordinate designations, records were kept of the number of aggressive acts emitted and received by the dominant and one subordinate fish of each group during the 20-min observation periods. Dominant fish emitted an average of 31 aggressive acts during this time and received none. The subordinate fish rarely initiated such acts $(\overline{\mathrm{X}}<1.0)$ and received an average of six. The other acts emitted by the dominant individual were distributed across the other three subordinates in the tank.

\section{REFERENCES}

Allee, W. C. Recent studies in mass physiology. Biological Review, 1934, 9, 1-48.

Allee, W. C., \& Bowen, E. S. Studies in animal aggregations: Mass protection against colloidal silver among goldfishes. Journal of Experimental Zoology, 1932, 61, 185-207.

Chiszar, D., Drake, R. W., \& Windell, J. T. Aggressive behavior in rainbow trout (Salmo gairdneri Richardson) of two ages. Behavioral Biology, 1975, 13, 425-431.

DAvis, R. E. Readiness to display in the paradise fish
Macropodus opercularis, and the problem of general and specific reactivity. Behavioral Biology, 1976, in press.

Escobar, R. A., Miniahan, R. P., \& Shaw, R. J. Motility factors in mass physiology: Locomotor activity of fishes under conditions of isolation, homotypic grouping and heterotypic grouping. Physiological Zoology, 1936, 9, 66-78.

GREENBERG, B. Some relations between territory, social hierarchy, and leadership in green sunfish (Lepomis cyanellus). Physiological Zoology, 1947, 20, 267-299.

HALE, E. B. Social facilitation and forebrain function in maze performance of green sunfish (Lepomis cyanellus). Physiological Zoology, 1956, 24, 93-107.

Henderson, D. L., \& Chiszar, D. A. Analysis of aggressive behavior in the bluegill sunfish, Lepomis macrochirus Rafinesque: Effects of sex and size. Animal Behaviour, in press.

Huck, L., \& Gunning, G. Behavior of the longear sunfish, Lepomis megalotis (Rafinesque). Tulane Studies in Zoology, 1967, 14, 121-131.

Poulsen, H. R., \& ChiszaR, D. Interaction of predation and intraspecific aggression in bluegill sunfish (Lepomis macrochirus). Behaviour, 1975, 55, 268-286.

SCHLAIfER, A. Studies in mass physiology: Effect of numbers upon the $\mathrm{O}_{2}$ consumption and locomotor activity of Carassius auratus. Physiological Zoology, 1938, 11, 408-424.

ShAw, G. The effect of biologically conditioned water upon rate of growth in fishes and amphibia. Ecology, 1932. 18, 263-278.

WELTY, W. Experiments in the group behavior of fishes. Physiological Review, 1934, 7, 88-128.

Wijffels, H., Thines, G., Dijkgraaf, S., \& Verheijen, F. J. Apprentissage d'un labyrinthe simple par des teleosteon isole ou groupes de vespele barbus ticto. Archives Néerlandaises de Zoologie, 1967, 17, 376-402.

(Received for publication March 9, 1976.) 